\title{
The Improvement Of Quality Of Solid Block Concrete On Commercial Industry In Palangka Raya, Central Kalimantan Province
}

\section{Peningkatan Kualitas Batako Solid Block Mutu Tinggi Pada Industri Rumah Tangga Di Kota Palangka Raya, Provinsi Kalimantan Tengah}

\author{
Revianti Coenraad ${ }^{1)}$ \\ 1), Program Studi Pendidikan Teknik Bangunan, FKIP, UPR \\ Kampus Unpar Tunjung Nyaho, Jl. H. Timang, 73111A
}

e-mail: revycoenraad@yahoo.co.id

\begin{abstract}
The intention of Program Kemitraan Masyarakat Stimulus (PKMS), The Cooperated Program of Stimulus Community, is providing the training and empowerment on the process of concrete brick making to the cooperated group maker of solid concrete brick product at around Palangka Raya to enhance the product quality for the solid block (non-hole concrete brick) to be high quality with low price per unit, as well to improve the market demand of relating its product. The objective of this program is in order to be able improving the income of cooperated group maker of solid concrete brick product without disregarding the quality of produced concrete brick. The target of cooperation for this program, PKMS, is the home industry of concrete brick making owned by Mr. Ino and Mr. Alpi where are located at subdistrict of Panarung. The method used in this is the training, guidance, and further cross checking with some solutions in the production and marketing part. The training and guidance are implemented to achieve the high quality of solid block of concrete brick, followed by the knowledge of basic raw material, design of mixed model, maintenance, and testing of concrete brick quality. The main output will be the enhancement of solid block of concrete brick with high quality product. This activity will be published on the scientific and engineering publication such as journal and final report.
\end{abstract}

Keywords: Solid Block of Concrete Brick, Training, Guidance

\section{ABSTRAK}

Maksud kegiatan Program Kemitraan Masyarakat Stimulus (PKMS) adalah memberikan pelatihan dan pendampingan pada pembuatan batako kepada mitra usaha kelompok pembuat batako solid block di Palangka Raya untuk meningkatkan kualitas batako tidak berlubang (solid block) menjadi mutu tinggi dengan harga yang murah, serta untuk meningkatkan pemasaran batako tidak berlubang. Tujuan kegiatan ini adalah agar mitra kelompok usaha batako dapat meningkatkan pendapatannya tanpa mengesampingkan kualitas batako yang diproduksinya. Mitra yang menjadi sasaran PKMS ini adalah industri pembuatan batako milik Bapak Ino dan Bapak Alpi yang berlokasi di kelurahan Panarung. Metode yang digunakan adalah pelatihan, pendampingan, dan tindak lanjut dengan solusi di bidang produksi dan pemasaran. Pelatihan dan pendampingan produksi agar kualitas batako solid block mutu tinggi, dengan pengetahuan kualitas bahan dasar, desain perancangan campuran, perawatan, dan pengujian kualitas batako. Luaran yang dihasilkan melalui kegiatan PKMS ini adalah peningkatan kualitas batako solid block dengan mutu tinggi. Kegiatan akan dipublikasikan dengan artikel ilmiah yang akan diterbitkan dalam jurnal dan laporan kegiatan.

Kata Kunci: Batako solid block, Pelatihan, Pendampingan

\section{PENDAHULUAN}

Batako merupakan bahan/material bangunan yang paling banyak digunakan khususnya di Indonesia. Sebenarnya batako termasuk dalam jenis beton. Hanya saja masyarakat Indonesia lebih familiar dengan sebutan batako. Pengunaan beton sebagai material bangunan saat ini sudah sangat umum dan telah dibuktikan oleh waktu sebagai bahan dinding yang tahan gempa. Beton dapat diproduksi dengan tangan dan mesin. Penggunaan khusus beton ditentukan oleh ukuran dan mutunya. Salah satu jenis beton yang cukup familiar dikalangan masyarakat adalah batako.
Banyaknya pembangunan perumahan dan ruko di Kota Palangka Raya menyebabkan meningkatnya kebutuhan bahan bangunan, termasuk batako. Developer lebih memilih menggunakan batako dibandingkan dengan batu bata karena harga batako relatif lebih murah, sehingga berdampak pada harga jual rumah. Hal tersebut menyebabkan industri batako skala kecil berkembang dengan pesat di Kota Palangka Raya, akan tetapi tidak diimbangi dengan pengetahuan yang cukup dari pelaku usaha untuk menghasilkan batako yang berkualitas. Para pembeli juga tidak memberikan perhatian terhadap 
kualitas, yang penting harganya murah. Kondisi tersebut berdampak pada kualitas bangunan yang dihasilkan.

Situasi pembuatan batako baik batako yang berlubang (hollow block) maupun batako tidak berlubang (solid block) di Kota Palangka Raya saat ini adalah (1) umumnya masih menggunakan metode konvensional yang berbahan dasar pasir, semen dan air, (2) kekuatan dan keawetan batako yang umumnya belum masuk dalam kategori kualitas baik karena kuat tekannya masih di bawah $70 \mathrm{~kg} / \mathrm{cm}^{2}$ (SNI-03-0349-89). Salah satu alasan bagi pengusaha batako di Kota Palangka Raya mengenai mutu batako yang masih rendah tersebut dikarenakan harga semen yang mahal. Sementara untuk menaikkan mutu batako berupa meningkatkan kuat tekannya membutuhkan semen yang lebih banyak karena kekuatan dan keawetan batako sebagian besar diperoleh dari semen. Bila pengusaha batako ingin meningkatkan mutu batako yang diproduksinya sesuai SNI-03-0349-89 dengan pemakaian semen yang lebih banyak maka biaya produksinya akan bertambah besar dimana harga satuannya relatif tetap sehingga akan membuat usaha pembuatan batako menjadi tidak ekonomis lagi. Dengan demikian dibutuhkan suatu usaha untuk mencari solusi yang mudah didapatkan dan harga relatif jauh lebih murah untuk digunakan dalam pembuatan batako.
Adapun justifikasi persoalan mitra dari hasil pemantauan di lapangan adalah dari segi produksi: rendahnya kualitas batako solid block yang dibuat oleh mitra. Semakin sulitnya mempertahankan kualitas batako yang diproduksi yang diakibatkan oleh semakin tingginya harga semen, pengetahuan akan proporsi pencampuran bahan pembuat batako solid block yang terbatas, bahkan terkadang susah mendapatkannya pada waktu-waktu tertentu. Tingginya harga material pembentuk batako terutama semen menyebabkan keuntungan dan pendapatan yang diperoleh kelompok usaha batako menjadi semakin kecil. Kondisi tersebut membuat mitra pengurangi penggunaan semen atau merubah ukuran batako menjadi lebih kecil dari ukuran standar untuk menutupi biaya produksinya dan mencari keuntungan yang lebih layak. Mitra mempunyai keterbatasan informasi mengenai adanya teknik pembuatan batako yang berkualitas karena keterbatasan pengetahuan teknis tentang batako .

Merujuk pada permasalahan mitra tersebut, maka solusi yang ditawarkan kepada mitra adalah dengan transfer ipteks berupa pelatihan dan pendampingan usaha dalam bidang produksi dan pemasaran. Desain mengatasi permasalahan mitra dapat ditunjukkan pada Gambar 1.

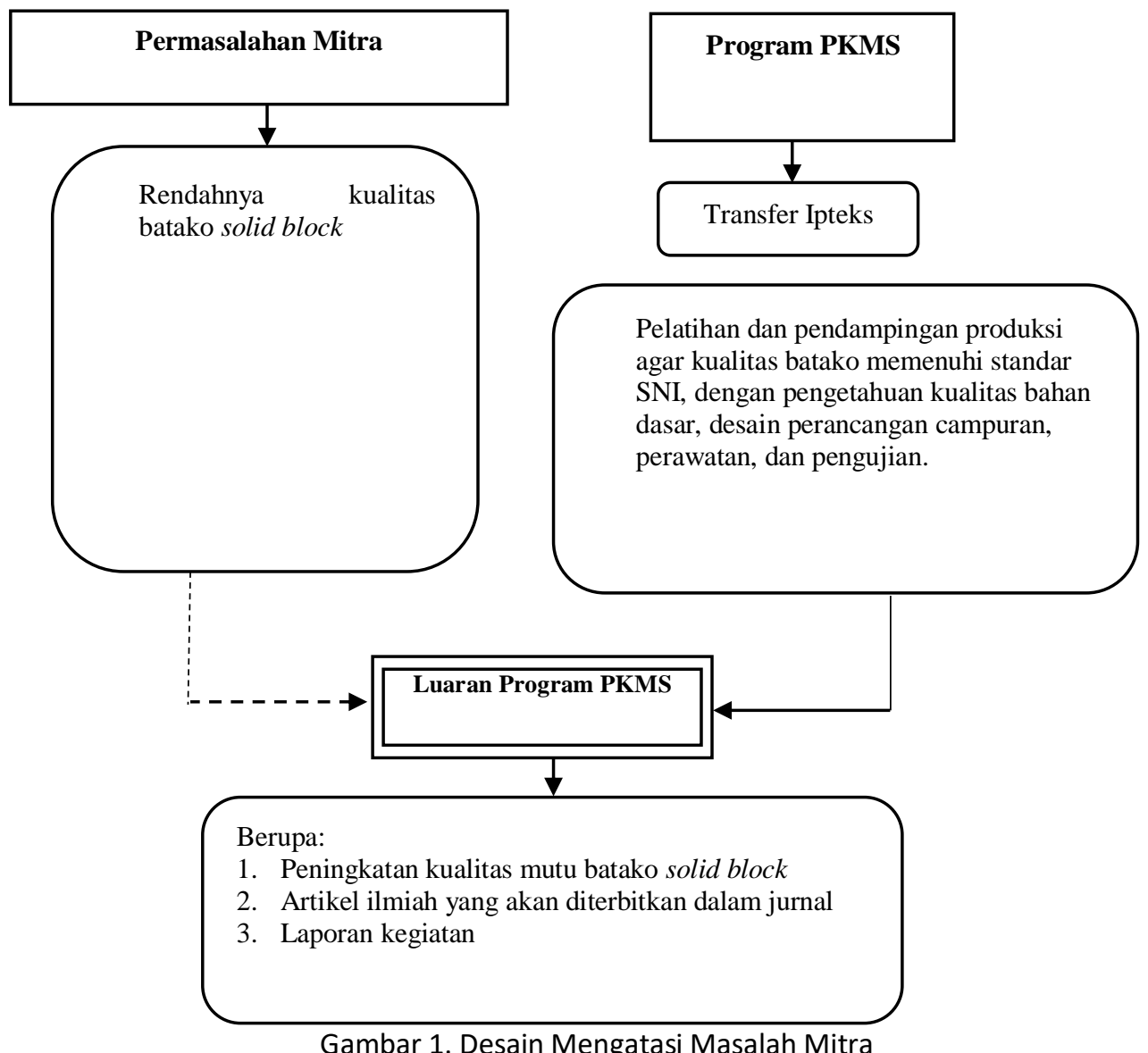



Kegiatan PKMS ini diharapkan memberikan dampak positif yang dijelaskan sebagai berikut:

(1). Potensi Ekonomis Produk

Batako yang dihasilkan melalui program ipteks ini mempunyai mutu yang lebih baik.

(2). Nilai Tambah Produk dari Sisi Iptek

a. Melalui program PKMS usaha pembuatan batako ini, pengusaha pembuat batako diberikan pengetahuan tentang cara pembuatan batako yang benar, pemakaian material aditif dalam pembuatan batako untuk mendapatkan batako yang bermutu baik dengan pemakaian semen yang lebih sedikit sehingga biaya produksinya dapat ditekan, serta perawatan batako agar kekuatannya meningkat.

b. Melalui program PKM usaha pembuatan batako ini diharapkan terlaksananya sharing pengetahuan/teknologi pembuatan batako dengan masyarakat (pengusaha batako) di Palangka Raya diharapkan kualitas batako yang ada di pasaran dapat lebih baik yaitu sesuai spesifikasi SNI-03-0349-89. Batako yang dihasilkan dengan perancangan campuran yang khusus akan diuji kuat tekan, uji jatuh, dan uji gores, hasil pengujian tersebut akan digunakan menjadi salah satu bagian dari promosi kualitas pada saat pemasaran produk.

(3). Dampak Sosial Secara Nasional

Pembuatan batako dengan mutu yang baik, yang memenuhi SNI-03-0349-89 sehingga konsumen pemakai batako merasa terjamin keamanannya dalam menggunakan batako (Kementerian Pekerjaan Umum, 2012), kualitas tersebut dapat dilihat pada hasil pengujian yang dilakukan di laboratorium PTB FKIP UPR pada sampel batako yang dibuat.

\section{METODE PELAKSANAAN}

Metode pendekatan yang ditawarkan kepada mitra antara lain:

1. Model pelatihan bagi mitra dilaksanakan sebelum pendampingan. Dalam pelatihan tersebut disampaikan teknik pembuatan batako yang berkualitas, dari tahap pemilihan dan pengujian bahan, tahap perencanaan campuran, tahap pengadukan dan pencetakan, dan tahap perawatan.
2. Model pendampingan masyarakat dalam penyelesaian permasalahan usaha batako. Pendampingan ini ditujukan sebagai upaya mengembangkan program edukasi kepada usaha batako melalui pola-pola yang lebih berorientasi pada peningkatan kualitas sumber daya manusia yang memiliki responsif dan tanggung jawab tinggi terhadap lingkungannya. Keterlibatan secara langsung bersama-sama mitra menghadapi dan menyelesaikan masalah, merupakan program pengabdian yang efektif. Karena selain memberikan manfaat langsung kepada masyarakat dalam hal ini kedua mitra yang terlibat disatu sisi pola ini secara akademis merupakan implementasi nilai-nilai keilmuan dosen yang mengembang tri dharma Perguruan Tinggi.

3. Model tindak lanjut. Tercapainya target program pada suatu kegiatan pengabdian belum dapat dijadikan indikator keberhasilan program dalam kerangka yang lebih luas. Masih banyak persoalan yang dihadapi oleh mitra baik sosial kemasyarakatan maupun fisik lingkungan yang belum tersentuh. Karenanya kami harapkan melalui kegiatan pengabdian ini akan terus berkembang untuk meningkatkan kesejahteraan para pengusaha batako khususnya melalui mitra yang dibina, sehingga dengan produksi yang bertambah, kualitas yang semakin bagus serta daerah pemasaran yang lebih luas lagi, yang terpenting metode pelaksanaan yang dapat mempercepat produksi, menghemat waktu dan menaurunkan harga jual sehingga mempercepat proses sirkulasi dana yang beredar di mitra, akan dapat meningkatkan kesejahteraan mitra.

Adapun posisi dari partisipasi mitra pada kegiatan pengabdian antara lain:

1. Mendukung pelaksanaan kegiatan PKMS agar terlaksana dengan baik dan lancar.

2. Mengikuti kegiatan pelatihan dari awal sampai dengan berakhirnya pelaksanaan.

3. Melaksanakan kegiatan produksi dengan menggunakan peralatan yang dimiliki mitra di lokasi usaha, dengan pendampingan intensif oleh tim pengabdi UPR. 


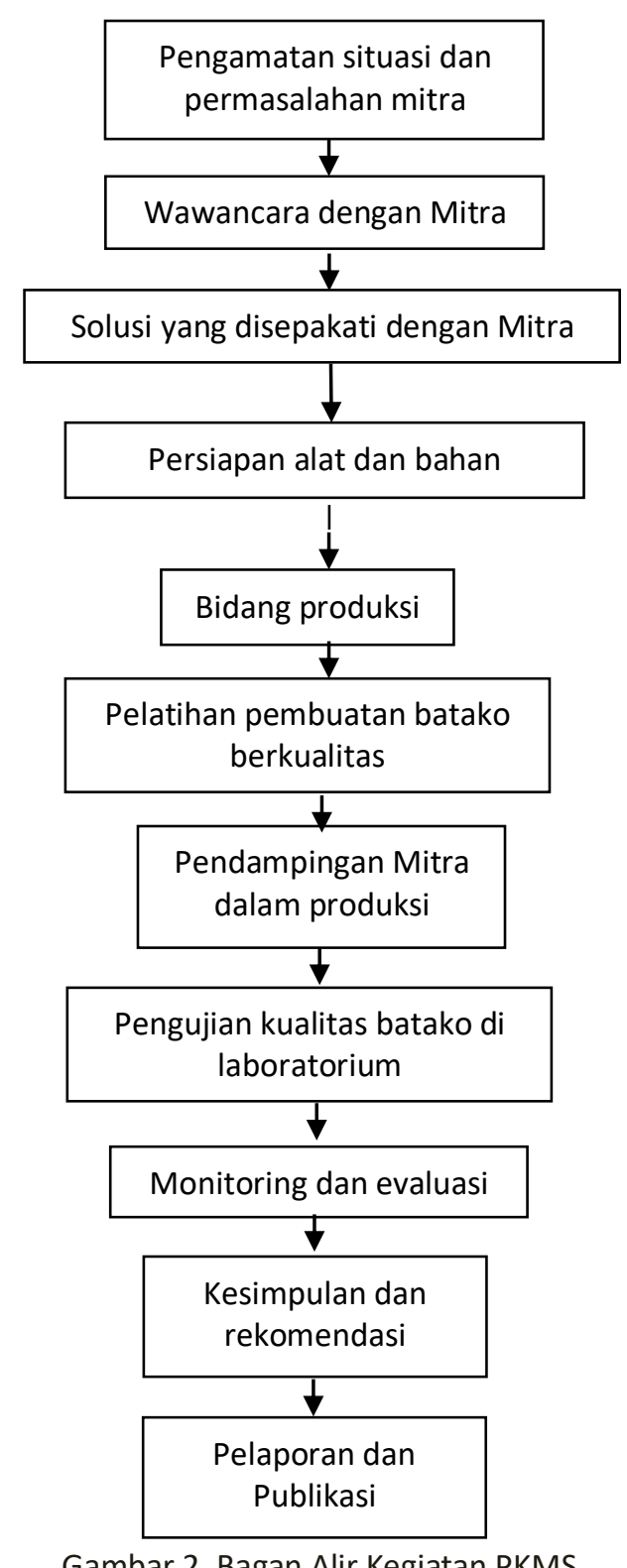

Gambar 2. Bagan Alir Kegiatan PKMS

\section{HASIL DAN PEMBAHASAN}

Dalam bidang produksi telah dilakukan pelatihan untuk teknik pembuatan batako solid block yang berkualitas, dari tahap pemilihan dan pengujian bahan, tahap perencanaan campuran, tahap pengadukan dan pencetakan, dan tahap perawatan, serta dilanjutkan dengan pendampingan. Pendampingan ini ditujukan sebagai upaya mengembangkan program edukasi kepada usaha batako melalui pola-pola yang lebih berorientasi pada peningkatan kualitas sumber daya manusia yang responsif dan memiliki tanggung jawab tinggi terhadap lingkungannya. Keterlibatan secara langsung bersamasama kedua mitra menghadapi dan menyelesaikan masalah, merupakan program pengabdian yang efektif.
Iptek yang akan ditransfer pada mitra untuk meningkatkan kualitas batako solid block agar memenuhi SNI dilakukan dengan memberikan pelatihan dan pendampingan. Pelatihan meliputi transfer pengetahuan tentang karakteristik batako. Untuk mendapatkan batako yang berkualitas, diperlukan pengetahuan tentang perilaku beton untuk mendapatkan nilai kuat tekan batako yang memenuhi syarat. Beberapa cara yang bisa dilakukan antara lain:

1. Membatasi jumlah pemakaian air pada campuran batako, karena rasio air dan semen mempengaruhi kekuatan batako.

2. Penggunaan bahan tambahan (aditif) berupa bahan mineral seperti fly ash (Mashuri, dkk, 2012), silica fume, dan lain-lain.

3. Penggunaan semen dengan kualitas yang tidak baik. 
4. Penggunaan obat beton, seperti superplasticizer.

5. Penggunaan pasir dengan modulus kehalusan yang cukup, gradasi yang baik, dan bersih dari lumpur dan kandungan organik

6. Perancangan campuran yang tepat berdasarkan kualitas bahan pembentuk batako.

7. Perawatan beton dengan metode curing yang benar.

8. Pemadatan yang maksimal

Menurut SNI-03-0349-89 tentang Persyaratan

Mutu bata beton berlubang maupun tidak berlubang (solid block), batako dibedakan atas:

a. Mutu I, yang digunakan untuk konstruksi yang tidak terlindung (di luar atap).

b. Mutu II, yang digunakan untuk konstruksi yang memikul beban, tetapi penggunaannya hanya untuk konstruksi yang terlindung dari cuaca luar (untuk konstruksi di bawah atap).

c. Mutu III, yang digunakan untuk konstruksi yang tidak memikul beban, untuk dinding penyekat serta konstruksi lainnya tetapi permukaannya tidak boleh diplester (di bawah atap).

d. Mutu IV, yang digunakan untuk konstruksi seperti penggunaan dalam mutu III tetapi selalu terlindungi dari hujan dan terik matahari (diplester dan di bawah atap)

Persyaratan mutu bata beton menurut SNI 030349-89 disajikan pada Tabel 1. Terdapat syarat ukuran standar dan toleransi dimensi batako (ukuran panjang, lebar dan tebal) seperti pada Tabel 2.

Tabel 1. Persyaratan Mutu Batako

\begin{tabular}{|l|c|c|c|c|c|}
\hline \multicolumn{1}{|c|}{ Persyaratan Mutu } & \multirow{2}{*}{ Satuan } & \multicolumn{4}{c|}{ Mutu Bata Beton Berlubang } \\
\cline { 3 - 6 } & & $\mathrm{I}$ & $\mathrm{II}$ & $\mathrm{III}$ & $\mathrm{IV}$ \\
\hline Kuat Tekan Bruto dan Rata rata minimum & $\mathrm{Kg} / \mathrm{cm}^{2}$ & 70 & 50 & 35 & 20 \\
\hline $\begin{array}{l}\text { Kuat Tekan Bruto masing masing Benda } \\
\text { Uji, minimum }\end{array}$ & $\mathrm{Kg} / \mathrm{cm}^{2}$ & 65 & 45 & 30 & 17 \\
\hline Penyerapan Air Rata rata, maksimum & $\%$ & 25 & 35 & - & - \\
\hline
\end{tabular}

Sumber: SNI- 03-0349-89

Tabel 2. Syarat Ukuran Standar dan Toleransi Ukuran Batako

\begin{tabular}{|l|c|c|c|c|c|}
\hline \multirow{2}{*}{ Jenis Bata Beton } & \multicolumn{2}{|c|}{ Ukuran dan Standar $(\mathrm{mm})$} & \multicolumn{2}{c|}{$\begin{array}{c}\text { Tebal Dinding Sekatan } \\
\text { Lubang }(\mathrm{mm})\end{array}$} \\
\cline { 2 - 6 } & panjang & Lebar & tebal & luar & Dalam \\
\hline Kecil & $400 \pm 3$ & $200 \pm 3$ & $100 \pm 2$ & 20 & 15 \\
\hline Besar & $400 \pm 3$ & $200 \pm 3$ & $100 \pm 2$ & 25 & 20 \\
\hline
\end{tabular}

Sumber: SNI- 03-0349-89

Untuk mengetahui kualitas batako yang memenuhi persyaratan SNI, maka terdapat beberapa pengujian yang dilakukan, antara lain: (Modul Pelatihan Pembuatan Batako (Muller, C., 2006): a. Uji Jatuh. Batu bata dan batako seharusnya tidak patah ketika dijatuhkan pada tanah yang keras dari ketinggian sekitar 1 meter. Cara pelaksanaan Uji Jatuh batako dapat dilihat pada Gambar 3 .

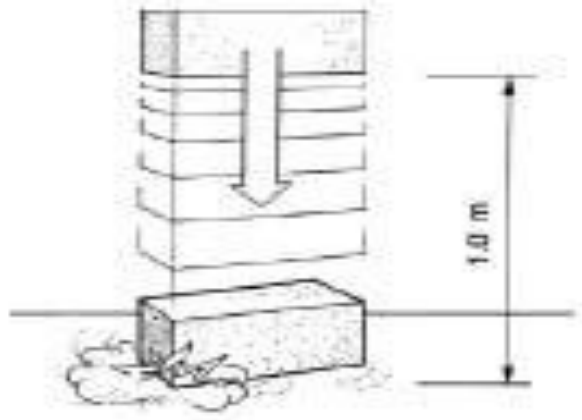

Gambar 3. Cara Pemeriksaan Batako dengan Uji Jatuh Sumber: Muller C. (2006) 

b. Uji Gores. Batako yang dicuring dengan benar memiliki permukaan yang cukup keras sehingga kuku tidak dapat menggoresnya.

c. Uji kuat tekan beton dengan menggunakan compression machine.

\section{KESIMPULAN DAN SARAN}

Adapun kesimpulan dan saran yang dapat diambil antara lain:

1. Kegiatan PKMS ini secara umum berjalan dengan lancar, sesuai dengan jadwal, selanjutnya rencana kegiatan pada tahap berikutnya berdasarkan jadwal kegiatan adalah monitoring dan evaluasi kegiatan, kesimpulan dan rekomendasi, serta pelaporan dan publikasi..

2. Mitra menyambut dengan baik kegiatan PKMS yang dilaksanakan oleh Universitas Palangka Raya, memberikan manfaat bagi mitra.
3. Mengingat banyaknya kegiatan pengabdian yang dapat dilakukan, Tim Pelaksana berharap, ke depan dana/pagu untuk kegiatan seperti ini dapat ditingkatkan/diperbesar, sehingga masyarakat yang mendapatkan manfaat kegiatan PKMS dapat lebih luas.

\section{DAFTAR PUSTAKA}

[1]. Badan Standardisasi Nasional, 1989, SNI 030349-1989, Sistem Informasi Standar Nasional Indonesia (SISNI). Jakarta.

[2]. Kementerian Pekerjaan Umum (2012), Pedoman Bahan Kontruksi Bangunan dan Rekayasa Sipil, Jakarta.

[3]. Mashuri, dkk. 2012. Penggunaan Abu Terbang Batubara pada Pembuata Batako di kota Palu, Mektek Tahun XIV No, 3, September 2012. 